\title{
Políticas locais de reestruturação curricular por ciclos: avanços e desafios
}

\author{
ANA CAROLINA CHRISTOFARI \\ Rede Municipal de Educação de Porto Alegre \\ KÁTIA SILVA SANTOS \\ Instituto Federal de Educação Ciências e Tecnologia da Bahia
}

\section{A “DUPLA VISÃO”}

A constituição de um texto que tem como característica a trama/junção de duas pesquisas é uma tarefa complexa, pois implica resgatar conteúdo e formas de estudos produzidos em contextos diferenciados, mas que apresentam pontos de aproximação. O presente texto tem como objetivo a análise dos atuais movimentos institucionais que caracterizam as políticas locais de reestruturação curricular por ciclos das redes municipais de ensino de Porto Alegre-RS (RME/POA) e de Vitória da Conquista-BA (RME/VC), dando ênfase ao processo de implementação.

Iniciando nosso diálogo sobre conteúdo e forma, destacamos que nosso "olhar" estará focado na perspectiva educacional que ambas as redes têm conduzido no processo de reestruturação curricular. Tal perspectiva parece indicar a aposta na educabilidade de todos os sujeitos; a ampliação do acesso e permanência de alunos de classes populares; a instituição de alternativas de construção de espaços e tempos escolares que têm favorecido o processo de escolarização de alunos com deficiência. ${ }^{1}$

1 O termo necessidades educativas especiais foi amplamente difundido a partir de 1978, com base no Relatório Warnock. No entanto, refere-se a um conjunto muito amplo de sujeitos. A Política Nacional de Educação Especial, na perspectiva da educação inclusiva 
É importante destacar que as redes têm em comum a existência de uma perspectiva teórica que apresenta pontos de sintonia com a pedagogia dialógica e com a abordagem histórico-cultural. É possível observar que há movimentos que indicam uma busca de alterações na escola, com a valorização de dispositivos que visam à flexibilização curricular e à implementação de apoios pedagógicos. Nas duas redes, é possível se sinalizar pontos de divergência daquilo que é indicado nas diretrizes e o que se faz no interior das escolas.

Há necessidade de uma leitura atualizada das políticas dessas redes, objetivando apresentar as atuais diretrizes e a análise dos possíveis efeitos no cotidiano e na prática pedagógica, apontando pontos em que os movimentos institucionais e políticos se aproximam e se diferem. Por ambas as redes serem organizadas por ciclos, podemos considerar que os municípios estudados, apresentados e analisados aqui, estão em consonância com os desafios contemporâneos da inclusão escolar. Essa forma de organização curricular teve como um dos seus principais objetivos, e talvez ainda tenha, alterar a organização da escola e buscar construir um modo de estruturá-la de forma mais coerente com as necessidades contemporâneas.

Os passos para apresentar a presente análise são: uma necessária revisão dos princípios e das ações que caracterizam a RME/POA e a RME/VC, desde o início de década de 1990 até 2010; a apresentação da metodologia que orientou a presente análise e a discussão que procura estabelecer os nexos entre os atuais momentos das redes de ensino em questão.

\section{INTERPRETANDO CONTEXTOS}

Os trabalhos de investigação que dão sustentação à presente análise foram desenvolvidos por meio de ações características de uma pesquisa de cunho qualitativo, já que esta se relaciona à variabilidade de estratégias metodológicas. É importante destacar que será apresentada uma versão, entre tantas possíveis, da "história" do processo de reorganização curricular em ciclos nesses municípios.

Para compreender os movimentos das redes municipais em questão, analisá-las e construir uma visão crítica atinente às suas organizações, trabalhamos com entrevistas dirigidas a gestores e educadores das redes. As entrevistas foram gravadas e transcritas, realizando-se sucessivas leituras do material. Houve uma intensa inserção em escolas municipais, participação em conselhos de classe, reuniões pedagógicas, observação de aulas e coleta de materiais, que foram organizados por eixos temáticos para serem analisados.

Com base nesse movimento, neste texto os eixos temáticos foram organizados da seguinte maneira: a lógica dos ciclos; organização curricular da RME/POA; organização curricular da RME/VC; pontos de aproximação e convergências entre as referidas redes.

de 2008, define os alunos da educação especial sendo aqueles com deficiência, com transtornos globais de desenvolvimento e altas habilidades. Neste texto, utilizaremos alunos com deficiência para nos referir ao conjunto de alunos da educação especial atual. 
Compreendendo a lógica dos ciclos

A lógica que tem sustentado a organização curricular por ciclos parece objetivar uma modificação na histórica organização da escola por sistema seriado, pois há uma mudança de uma prática que considera o prazo de um ano de "formação", a série escolar, para ciclos de dois, três ou mais anos, ou ainda etapas anuais. Essa lógica indica um tipo de flexibilização do tempo escolar. Desse modo, a organização curricular pode ser baseada, por exemplo, em ciclos que atendem a etapas da vida denominadas de infância, pré-adolescência e adolescência. Essa forma de organização privilegia o desenvolvimento em todos os aspectos, podendo existir maior sensibilidade acerca da diversidade das relações com o saber, da maneira de aprender, do ritmo de desenvolvimento, da identidade e trajetória de cada sujeito.

As mudanças que se operam nas práticas pedagógicas e no currículo escolar inovam em relação àquela lógica escolar com uma preocupação direcionada aos conteúdos trabalhados de maneira isolada e da avaliação seletiva, por vezes discriminatória e excludente. Tais transformações podem auxiliar na ruptura com o enciclopedismo, com a simples memorização de fatos e regras e na valorização de um processo de continuidade das aprendizagens em sua forma cíclica em "espiral". Busca-se navegar, portanto, em sentido contrário à "pedagogia bancária”, na qual o aluno era visto como mero receptor de informações sem ter espaço de participação em seu próprio processo educacional. A lógica que sustenta uma organização curricular por ciclos ultrapassa uma preocupação com os conteúdos de maneira isolada, enquadrada num tempo previsto para ser trabalhado. Nesse sentido é que se discute a flexibilização dos tempos de aprender de cada aluno e o que é importante aprender em cada etapa do desenvolvimento humano.

Nessa perspectiva, objetiva-se proporcionar aos alunos trajetórias educacionais mais fecundas, criando condições favoráveis para o uso do tempo na vigência de cada período, por meio de agrupamentos ${ }^{2}$ por idade e objetivos ao final de cada ciclo, que não necessariamente se desdobram em programas rígidos e lineares. $\mathrm{O}$ que não significa falta de uma organização curricular e temáticas específicas a serem trabalhadas em cada ano/ciclo.

Nessa mesma lógica, o processo avaliativo busca compreender as singularidades da aprendizagem do aluno e as estratégias necessárias para o seu desenvolvimento. Dessa maneira, as práticas de avaliação em organizações curriculares por ciclos objetivam considerar o processo contínuo de escolarização levando em conta a avaliação da aprendizagem como retroalimentação das práticas pedagógicas dos professores. A avaliação faz-se necessária como ferramenta de indicativos da relação pedagógica e do desenvolvimento do aluno, sem que seja feita comparação

2 Agrupamentos são os modos de organização das turmas que no sistema seriado era realizada tomando como base os conhecimentos. Na lógica dos ciclos, as "enturmações" estão relacionadas à idade dos alunos, considerando que a fase de desenvolvimento e os interesses podem estar em certa sintonia. 
deste com os demais, buscando a homogeneização. A individualização dos percursos de aprendizagem no ensino é uma das estratégias adotadas por esse tipo de organização escolar (Perrenoud, 2004). O processo de aprendizagem é focado nas possibilidades de desenvolvimento individual, considerando as peculiaridades do modo de aprender e se expressar de cada aluno. Esse modo de conceber o processo de avaliação parece indicar um afastamento de uma lógica da homogeneização dos ritmos e aprendizagens.

Para favorecer esse movimento, a escola organizada por ciclos tenta dar forma a uma multiplicidade de dispositivos que indicam a flexibilidade de sua estrutura. Estão presentes estratégias como, por exemplo, o apoio pedagógico. Quando o aluno apresenta dificuldades de aprendizagem, esse auxílio se dá por meio de professores de apoio e itinerantes, ${ }^{3}$ Sala de Integração e Recursos (SIR) e Laboratório de Aprendizagem (LA).

Assim, percebe-se que a organização escolar por ciclos não pretende representar uma mera mudança nos detalhes do funcionamento da escola, nas denominações das ações desenvolvidas, mas favorecer uma profunda modificação em toda a estrutura da instituição, bem como na concepção de toda comunidade escolar acerca do que é e para que serve a escola.

\section{A política dos ciclos no Brasil: breve panorama}

A organização escolar por ciclos faz-se presente em países como a Espanha, França, Argentina (nível federal) e alguns estados dos Estados Unidos da Améria (EUA). No Brasil, a escola por ciclos começou a ganhar espaço como uma tentativa de contribuir com a mudança educacional, começando pelo interior da própria escola (Barbosa,2004). Criaram-se, na década de 1980, modos diversos de pensar os tempos e espaços escolares, incluindo-se a ideia de tempos prolongados, turmas de progressão, turmas de aceleração, isto é, toda uma nova concepção de temporalidades na escola. A organização da escola em ciclos foi implantada em muitas cidades brasileiras e em cada local essa forma de organização foi assumindo suas particularidades.

Os ciclos de aprendizagem, assim como os ciclos de formação, ${ }^{4}$ ao serem implantados, objetivavam ampliar o tempo de aprendizagem, diminuir as taxas de

$3 \mathrm{Na} \mathrm{RME} / \mathrm{VC}$, são chamados professores de apoio; e na RME/POA são professores itinerantes. A função desses professores (apoio e itinerante) é semelhante em ambas as redes, pois se refere a uma espécie de docência compartilhada. Esses professores entram em sala de aula com professores referência para construir estratégias de trabalho que possam ser acessíveis à diversidade humana. No entanto, em alguns casos, percebe-se que os professores de apoio ou itinerantes têm exercido função de substituição, ou seja, ingressam em sala de aula sem o professor referência, o que pode enfraquecer a intenção de uma docência compartilhada como qualificação do processo de ensino e aprendizagem.

4 Nos ciclos de aprendizagem, a organização dos grupos de alunos e a promoção são baseadas na idade cronológica. Os ciclos podem ser de dois ou três anos de duração, e os alunos que são considerados como não tendo atingido os objetivos do ciclo podem ser reprovados. De acordo com Mainardes (2006), essa proposta é vista como menos radical, consi- 
evasão e reprovação e, sobretudo, repensar modos de flexibilizar espaços e tempos escolares. As diretrizes que orientam a organização dos ciclos de formação sugerem que as práticas pedagógicas sejam pautadas nas necessidades dos alunos, articulando os conhecimentos prévios de cada um com os assuntos estudados. Além disso, a intenção de uma organização curricular dessa natureza é oportunizar que os alunos tenham diferentes espaços de aprendizagem e possam construí-la num tempo mais amplo. Outra característica dos ciclos é o ingresso das crianças na escola aos 6 anos, ampliando o período do ensino fundamental para nove anos.

Em uma retrospectiva histórica mais abrangente realizada sobre o tema, Barretto e Mitrulis (1999, p. 27-48 apud Barretto; Sousa, 2004) registram discussões sobre a promoção automática nos anos de 1950, suscitadas pelos elevados índices de retenção na escola primária brasileira, as experiências de implantação de ciclos levadas a cabo em diferentes estados nas décadas de 1960 e 1970, a adoção dos ciclos de alfabetização por vários governos estaduais na década de 1980, a criação dos ciclos de formação abrangendo o ensino fundamental completo nas propostas político-pedagógicas autodenominadas de radicais nos anos de 1990. Registra-se ainda a expansão do regime de ciclos nas diversas redes municipais no ano de 2000.

Segundo Barretto e Sousa (2004), no ano de 2002, 19,45\% das escolas brasileiras, públicas e privadas, encontravam-se organizadas em ciclos, sendo que $10,9 \%$ delas adotavam unicamente os ciclos e $8,5 \%$ combinavam ciclos e seriação. Outro dado relevante é que a maioria das escolas organizadas em ciclos se encontra situada nas regiões Sul e Sudeste. Em âmbito nacional, experiências que têm tido maior destaque são as da rede municipal de ensino de Porto Alegre, São Paulo e Belo Horizonte (escola plural).

É possível considerar que a organização curricular por ciclos está associada a uma concepção de que a escola seriada não estava dando conta da diversidade cultural, dos ritmos de aprendizagem e modos de vida dos alunos, fazendo com que muitos sujeitos ficassem à margem do processo de escolarização.

Nesse sentido, a escola por ciclos busca resgatar a ideia de valorização do sujeito e das diferentes culturas, relacionando conhecimento historicamente produzido com os diferentes modos de vida e cultura que se encontram na escola. Ou seja, a organização por ciclos faz um movimento de retomada de uma prática que atente para a importância de se construir uma interlocução entre o conhecimento científico e cultural sistematizado e aquele local, referente aos grupos que compõem a escola, de modo que afirme a identidade e modos de vida das crianças e adolescentes que a compõem.

derando as rupturas propostas atinentes ao currículo, avaliação, metodologia. No entanto, a estrutura organizativa dos ciclos de aprendizagem pode ser diferenciada conforme $o$ local de implantação. Já os ciclos de formação têm o objetivo de organizar o currículo de acordo com o desenvolvimento humano (infância, pré-adolescência e adolescência). Essa proposta é considerada mais radical, porque propõe mudanças no sistema de ensino e na organização escolar, julgadas mais profundas, e aponta a prática de não retenção dos alunos ao longo do ensino fundamental, exceto em situações de extrema necessidade. 
Há um discurso que considera a organização por ciclos a mais adequada em relação à aposta na educabilidade dos sujeitos. Apesar de a escola organizada por ciclos ser uma experiência relativamente nova em comparação aos anos que tivemos de escola seriada, é importante destacar pontos que se têm mostrado positivos ao processo de ensino-aprendizagem. Igualmente, refletir sobre as dificuldades existentes nesse modo de organização, apontando para uma prática em que há leituras diferenciadas em relação às propostas de ciclos, assim como há resistências em relação a desconstruir a ideia de ensino baseado nas concepções de uma escola seriada.

A lógica da escola ciclada direciona para uma inversão das concepções que temos de escola, ensino e aprendizagem e constituição humana. E isso significa nos desprender de toda construção moderna que se instaurou no imaginário coletivo sobre o que é uma escola e seu papel na sociedade.

\section{DESTACANDO OS “OLHARES”}

\section{Implementação e organização dos ciclos na RME/POA}

O contexto dos últimos 20 anos da RME/POA tem sido alvo de muitos estudos (Azevedo, 2000; Baptista; Dorneles, 2004; Bridi, 2004; Christofari, 2008; Moll, 2004; Tezzari, 2002; Xavier, 2003). Vários desses estudos mostram que, apesar de variações na organização do currículo, têm ocorrido mudanças no intuito da valorização da escolarização de sujeitos que estavam tendencialmente afastados da escola em razão de um perfil considerado destoante do aluno idealizado. É importante destacar que a maioria das escolas municipais é situada em regiões periféricas. Nesse sentido, há uma aproximação da escola com os alunos das classes populares e a busca de práticas educacionais que contemplem as singularidades culturais e de aprendizagem.

As discussões concernentes à implantação dos ciclos de formação na RME/ POA tiveram como marco a Constituinte Escolar da Secretaria Municipal de Educação ${ }^{5}$ (realizada em 1994 e 1995), que foi organizada como um espaço que buscava garantir e ampliar a participação popular. A proposta era embasada nos pensamentos de autores como Piaget, Vygotsky e Paulo Freire. Nesse espaço, foi oportunizado aos pais, alunos e funcionários das escolas da rede se manifestarem acerca de suas expectativas em relação à escola, respondendo a questões como: "Que escola temos? Que escola queremos?"

A constituinte pôs em pauta diferentes assuntos que davam sustentação ao combate à reprovação e evasão dos alunos. Além do mais, esse processo de discussão pretendeu pensar alternativas para a aproximação entre a escola e a comunidade. As discussões foram realizadas em grupos temáticos (currículo, avaliação, conhecimento, gestão, princípios de convivência) durante 18 meses.

5 Sobre o Congresso Constituinte Escolar em 1994, ler Cristiane Fiqueiró Klovan (2008). 
Vale também citar o projeto Escola Cidadã, ${ }^{6}$ que foi proposto pela Secretaria Municipal de Educação (SMED) de Porto Alegre no período da "Gestão Popular" liderada pelo Partido dos Trabalhadores (PT). A proposta do projeto era embasada nos princípios de democratização do ensino, das relações institucionais e, sobretudo, na democratização da participação popular com relação às questões referentes às estruturas organizacionais da escola. Essa proposta partia do princípio da importância e necessidade da participação da população nas decisões atinentes a melhoria da cidade de modo que as pessoas pudessem se sentir parte das decisões tomadas e assim responsáveis por elas também.

Com o princípio da educação na perspectiva da inclusão e da construção coletiva da escola para todos, a RME/POA colocou em evidência uma proposta que anunciava o objetivo de romper com os mecanismos de exclusão escolar, e, para isso, lançou a discussão sobre quais alternativas a escola poderia criar para que a educação fosse construída em direção à inclusão de todos os alunos na rede regular de ensino. Espaços como as SIRs, os LAs e as turmas de progressão foram pensados como um apoio para professores e alunos que estavam encontrando dificuldades no processo de ensino-aprendizagem. Nesse sentido, foi necessário organizar uma grade curricular pensando em como contemplar a heterogeneidade presente em sala de aula e como oferecer a todos os alunos um ensino que, diante das especificidades, fosse de qualidade, acessível e constante.

Cabe aqui ressaltar as alternativas de apoio pedagógico: $\operatorname{SIR}^{7}$ (atende alunos com deficiência); LA (atende alunos que encontram dificuldades no processo de aprendizagem); turmas de progressão (atende alunos com defasagem idade/escolaridade); estagiários $^{8}$ do curso de inclusão escolar. Para o ano de $2010,{ }^{9}$ de acordo com

6 Moacir Gadotti, em seu texto intitulado Escola cidadã: educação para e pela cidadania, discute o conceito de escola cidadã sinalizando que essa concepção foi construída num contexto de renovação e de práticas concretas para e pela cidadania, tendo o pensamento de Freire como um dos principais inspiradores. Segundo o autor, a escola cidadã faz parte de um projeto amplo da sociedade, que busca uma educação para e pela cidadania, que nasceu no final da década de 1980 na educação municipal. Gadotti afirma que: "Em Porto Alegre, capital do Estado do Rio Grande do Sul, durante a gestão de 1993-1996, dando continuidade à política educacional da gestão anterior, a Escola Cidadã constitui-se como eixo orientador de toda política educacional, baseada no planejamento participativo, na autonomia da escola como estratégia de qualidade de ensino e na construção da cidadania como prática pedagógica” (p. 7). Disponível em: <http://www.paulofreire.org/Moacir_Gadotti/Artigos/Portugues/Escola_Cidada/ Escola_Cid_Mov_projeto_2000.pdf>.Acesso em: 15 nov. 2011.

7 Atualmente (ano de 2012), somente quatro escolas municipais não têm implantado o serviço da SIR.

8 Esses estagiários são estudantes de pedagogia/educação especial. No ano de 2009, havia 138 estagiários do curso de inclusão nas escolas da rede.

9 Após 2010, as mudanças na organização das SIRs foram efetivadas. Atualmente (ano de 2012) há apenas um professor atuando, na maioria dos casos, em cada SIR. Esses professores têm, geralmente, carga horária de $40 \mathrm{~h}$ semanais e trabalham com grupos em média de 25 alunos no turno inverso ao que frequentam a sala de aula do ensino regular. 
dados da SMED,${ }^{10}$ há a intenção de aumentar tanto o número de alunos atendidos, quanto a quantidade de SIRs, modificando ainda a sua organização, que tem sido de dois professores trabalhando em sala de aula no mesmo turno, atendendo a diferentes alunos, passando para um professor por sala. A justificativa para essa mudança é de que essa ação oportunizaria um maior número de alunos atendidos.

No que se refere à avaliação, também houve mudanças significativas com a proposição da "avaliação emancipatória". Esta proposta tem sido considerada como possibilidade de fazer com que a prática da avaliação seja um instrumento de intervenção pedagógica da qual os professores possam usufruir visando ao conhecimento das potencialidades de seus alunos e também de suas estratégias pedagógicas. A prática da avaliação, nesse sentido, tem a intenção de romper com uma avaliação classificatória, segregacionista, em que o aluno é comparado com um padrão considerado ideal de aprendizado, de comportamento, de expressão.

Mesmo diante das críticas em relação a essa estrutura, no ano de 2000 todas as escolas já tinham adotado a lógica dos ciclos. Esse movimento teve início na "Gestão Popular”, que ficou no governo de Porto Alegre de 1989 até 2004. A organização curricular por ciclos de formação permanecem até os dias atuais.

A proposta dos ciclos na RME/POA tem como objetivo respeitar, dentro do possível, os ciclos da vida humana: infância, pré-adolescência e adolescência. Desse modo, as turmas de cada ciclo foram organizadas conforme a faixa etária e distribuídos em ciclos ${ }^{11}$ de três anos cada. Estruturando, portanto, o ensino fundamental em nove anos.

Quadro 1 - Organização curricular por ciclos, RME/POA

\begin{tabular}{|c|c|c|}
\hline Ciclos & Ano/ciclo & Apoios \\
\hline \multirow{3}{*}{$\begin{array}{l}\text { I Ciclo } \\
\text { Infância }\end{array}$} & $1^{\circ} \mathrm{A} 10(6 \text { anos })^{12}$ & \multirow{3}{*}{$\begin{array}{l}\text { Progressão AP } 13 \\
\text { Laboratório de Aprendizagem } \\
\text { Sala de Integração e Recursos }\end{array}$} \\
\hline & $2^{\circ} \mathrm{A} 20$ (7 anos) & \\
\hline & $3^{\circ} \mathrm{A} 30$ (8 anos) & \\
\hline \multirow{3}{*}{$\begin{array}{l}\text { II Ciclo } \\
\text { Pré-adolescência }\end{array}$} & $1^{\circ} \mathrm{B} 10$ (9 anos) & \multirow{3}{*}{$\begin{array}{l}\text { Progressão BP } \\
\text { Laboratório de Aprendizagem } \\
\text { Sala de Integração e Recursos }\end{array}$} \\
\hline & $2^{\circ} \mathrm{B} 20$ (10 anos) & \\
\hline & $3^{\circ} \mathrm{B} 30$ (11 anos) & \\
\hline \multirow{3}{*}{$\begin{array}{l}\text { III Ciclo } \\
\text { Adolescência }\end{array}$} & $1^{\circ} \mathrm{C} 10$ (12 anos) & \multirow{3}{*}{$\begin{array}{l}\text { Progressão CP } \\
\text { Laboratório de Aprendizagem } \\
\text { Sala de Integração e Recursos }\end{array}$} \\
\hline & $2^{\circ} \mathrm{C} 20$ (13 anos) & \\
\hline & $3^{\circ} \mathrm{C} 30$ (14 anos) & \\
\hline
\end{tabular}

Elaboração das autoras.

10 Informação apresentada pelos gestores da SMED em curso realizado para professores ingressantes na rede e em estágio probatório (três anos), em janeiro de 2010.

11 AI, AII, AIII (dos 6 aos 8 anos); BI, BII, BIII (dos 9 aos 11 anos); CI, CII e CIII (dos 12 aos 14 anos).

12 A10, A20, A30 (dos 6 aos 8 anos); B10, B20, B30 (dos 9 aos 11 anos); C10, C20, C30 (dos 12 aos 14 anos).

13 Progressão AP, BP, CP: turmas de progressão foram criadas como um espaço provisório para alunos com defasagem em relação à idade/escolaridade. Os alunos deveriam ficar 
A RME/POA, além dos recursos pedagógicos apresentados anteriormente, conta com um professor itinerante, cuja função seria de auxiliar o professor referência nas atividades cotidianas, estando junto em sala de aula, sendo um parceiro na reflexão, análise e construção do exercício pedagógico. Na prática, esse recurso humano, que deveria funcionar como docência compartilhada, foi tornando-se um modo de inserir o professor em ações de substituição. Ou seja, além de o professor itinerante não ter espaço de planejamento com o professor referência, ele substitui professores que faltam.

Nesse contexto, há grande reclamação dos próprios professores em relação a essa função e a revelação de que ninguém quer mais exercê-la, alegando que o substituto não tem uma ação conjunta com o professor referência, não compartilha ideias e vem assumindo a turma de alunos de maneira desconexa, sem poder construir um plano de ação e em muitos casos sem saber o que está sendo trabalhado.

Outra dificuldade bastante presente nas escolas é em relação à avaliação da aprendizagem. Para além dos debates atinentes ao modo de expressar a avaliação realizada pelos professores, está a discussão sobre retenção ou avanço dos alunos. Nesse sentido, há aqueles que acreditam que os alunos que avançam têm a possibilidade de prosseguirem seus estudos sem as tensões e os desgastes provocados pelo sistema seriado. Em contrapartida, há aqueles que questionam em relação ao destino dos alunos que progridem.

Muitos professores consideram que a retenção seria um modo de rever, juntamente com os alunos, as lacunas que ficaram, no intuito de buscar uma aprendizagem mais completa. Há muitas indagações sobre o que e como os alunos estão aprendendo, além da preocupação de que a progressão não se torne uma prática de desresponsabilização da escola pela oferta de um ensino de qualidade.

De acordo com Christofari (2008, p. 13),

É oportuno advertir que o solo que sustenta as discussões acerca da finalidade dos processos avaliativos nos Ciclos de Formação é bastante fértil. Há muito ainda a ser explorado e precisamos ter cuidado ao caminharmos sobre este solo, pois ele também é muito frágil. É fértil porque, ao ser discutido, permite brotar muitos frutos de reflexão no sentido de oportunizar questionamentos sobre o aprimoramento da prática pedagógica e os papéis da escola pública na atualidade. É frágil por ser uma discussão que trata de questões importantes que estruturam a educação escolar como, por exemplo: a construção curricular, os serviços pedagógicos destinados às crianças com dificuldades na aprendizagem, a prática pedagógica, entre outras.

no máximo dois anos nessas turmas e poderiam retornar ao ano/ciclo adequado em qualquer momento do ano letivo. Porém, foram tornando-se turmas de alunos com diferentes questões: cognitivas, comportamentais, relacionais. Essas turmas não são o foco desta discussão e, apesar de existirem em ambas as redes, não constituem um número significativo, nem na RME/POA nem na RME/VC. 
É importante destacar uma conquista dos professores da RME/ POA referente ao período semanal de planejamento. Todos os professores têm direito a quatro períodos semanais de planejamento, sendo cumpridos na escola ou em casa, dependendo da convenção interna.

Com a implantação dos ciclos, também houve reflexos no modo de pensar a educação especial, redirecionando as discussões que se mantinham numa análise médico-clínica em relação aos alunos com deficiência para encontrar alternativas de apoio pedagógico. Assim, esses alunos poderiam frequentar o ensino comum com possibilidade desse recurso, sem ficar em espaços destinados apenas às crianças com deficiência ou escolas especiais. No município de Porto Alegre não há mais classes de educação especial, mas a população pode contar com quatro escolas para essa educação, que são mantidas pela rede e também organizadas por ciclos. As escolas especiais estão organizadas em três ciclos, porém a idade é de 6 a 21 anos no processo de escolarização. Apesar das metas anunciadas, há estudos que têm destacado diferentes efeitos para esses espaços especializados, no intuito de um refinamento do controle, disciplinamento e também de um possível afastamento dos alunos para serem "normalizados".

Esses movimentos causados pela tentativa de ruptura com uma educação classificatória e, por vezes, excludente são vivenciados nas escolas e acompanhados de questionamentos quanto aos seus possíveis efeitos. Um dos pontos nodais na RME/POA, por exemplo, refere-se à progressão continuada dos alunos, que, apesar de os professores reconhecerem seus aspectos positivos, ainda encontram dificuldades no momento de colocar em prática uma avaliação que dê sustentação ao ato pedagógico.

Os movimentos que caracterizam a RME/POA continuam desafiando a todos a capacidade de compreensão de como construir diariamente uma escola pública pautada na articulação entre a qualidade e alternativas de atendimento às particularidades dos alunos. As maiores dificuldades encontram-se na mudança de concepções sobre ensino, aprendizagem e constituição de sujeitos que historicamente foram se arraigando no imaginário escolar. Vivemos uma época em que a diversidade humana se faz notar no âmbito escolar, mas a estrutura é aquela da escola moderna, cuja homogeneidade era condição.

\section{Política de reestruturação curricular na RME/VC}

Desde o ano de 1998, a RME/VC passou a organizar as escolas em ciclos. Trata-se de um período que também marca o início do que a gestão eleita denominou de "popular", com o PT assumindo a prefeitura desse município.

\section{Primeiro momento: ciclo de aprendizagem}

O processo de mudança da escola seriada para a ciclada marcou um momento no qual houve conflitos, assim como em Porto Alegre, pois se tratava de propor uma profunda mudança na concepção de educação, de ensino e de aprendizagem de todos os envolvidos. Houve relatos de alguns dos entrevistados quanto ao sentimento de 
despreparo e receio em relação à implantação dessa nova organização curricular. Tais conflitos foram evidenciados nas falas dos entrevistados que manifestaram a dificuldade na implantação, referindo-se à falta de material didático, de espaço, de informações mais específicas sobre a lógica dos ciclos.

Segundo Gomes (2003), em um país marcado pela "pedagogia da repetência”, é importante indagar de que maneira as experiências como as dos ciclos no ensino fundamental têm sido implementadas. Para esse autor, um dos enganos mais recorrentes no deslocamento da escola seriada para aquela ciclada seria a falta de discussão e assimilação da proposta.

O objetivo explicitado na primeira versão da proposta do ciclo de aprendizagem era romper como a lógica da seriação. A princípio, somente foi implantado o ciclo I, que estava subdividido em dois anos correspondentes a uma $1^{\mathrm{a}}$ e a uma $2^{a}$ série. Essa ação não conseguiu produzir mudanças significativas na organização curricular, mantendo-se a lógica de salas.

Gomes (2003) afirma que com a sombra da seriação mantida pelos professores, vários equívocos podem ser cometidos. Um desses equívocos seria a transferência da reprovação para o fim do ano/ciclo. No caso do município estudado, repetência se manteve no final do $2^{\circ}$ ano do ciclo $\mathrm{I}$, chamado de $2^{\mathrm{a}}$ fase.

A partir de 2000, houve em toda a RME/VC a percepção de que o ciclo I, implantado apenas em dois anos (para alunos de 7 e 8 anos), não atendia às expectativas dos professores e da comunidade escolar em geral, já que um dos seus principais objetivos não estava sendo alcançado: alterar a estrutura linear da seriação e consequentemente diminuir o alto índice de evasão e repetência. Leite (1999) reforça essa ideia quando afirma que a implantação dos ciclos de aprendizagem nas escolas municipais de Vitória da Conquista teria como uma das causas principais a tentativa de minimizar a reprovação/repetência escolar. Após esta primeira e difícil tentativa de implantação da escola organizada em ciclos, a rede municipal retorna à organização em séries durante todo o ano de 2001. Um momento que pode ser interpretado como uma tentativa por parte da secretária de educação de retomada do "fôlego" para dar curso a novas mudanças.

Nesse sentido, no ano de 2001 foram realizados vários fóruns de debate e estudos relacionados à organização em ciclos e a organização em séries. A SMED, então, decidiu ressignificar a proposta. A rede passava pelo primeiro movimento de reestruturação dos ciclos. O redimensionamento dos ciclos de aprendizagem estava sendo acompanhado por professores, coordenadores, diretores e pais.

Com base nesses fóruns e debates, houve a busca de ressignificação da organização curricular, passando a existir: o ciclo I com três anos (de 6 a 8 anos e 11 meses de idade); o ciclo II, equivalente a dois anos de escolarização (de 9 a 10 anos e 11 meses de idade). Tais mudanças envolveram, a princípio, dez escolas da zona urbana.

Nessa segunda versão da proposta dos ciclos de aprendizagem, o ensino passou a ser organizado nas seguintes áreas do conhecimento: conhecimentos linguísticos, raciocínio lógico matemático, ciências naturais, ciências socioculturais, atividades artísticas e desportivas. Entre as modificações relativas à própria estrutura 
escolar por ciclos, no que diz respeito à enturmação por idade, destacam-se algumas particularidades que passaram a caracterizar a escola ciclada desse município:

a Constituição das turmas de progressão, as quais eram classes de circulação entre os ciclos; ${ }^{14}$

b| Incorporação dos professores de apoio destinados a realizar um trabalho com alunos que apresentavam dificuldades na aprendizagem durante as etapas do ciclo;

c Capacitação permanente dos profissionais da escola;

d| Avaliação, que passou a objetivar a formação, pautando-se em instrumentos como pareceres descritivos, a autoavaliação, o conselho de classe;

e Promoção interciclo, sendo que ao final de cada ciclo, caso o aluno não tivesse adquirido as competências e habilidades necessárias para promoção, deveria ser encaminhado para as turmas de progressão;

f | Enturmação por idade e por nível de desenvolvimento formativo, observando critérios como: idade, desenvolvimento cognitivo, desenvolvimento sócio-histórico, cultural e afetivo.

Dois aspectos dessas inovações merecem ser destacados. O primeiro refere-se às turmas de progressão. Tais turmas foram pensadas para os alunos que apresentavam dificuldades de aprendizagem. Assim, as turmas de progressão, além de receberem os alunos com defasagem de idade e escolaridade, acabaram tornando-se o espaço destinado aos alunos com dificuldades de aprendizagem.

$\mathrm{O}$ segundo aspecto refere-se aos professores de apoio à aprendizagem. Todavia, não havia nas escolas da rede municipal um profissional específico para realizar tais atividades objetivando o avanço dos alunos. $\mathrm{Na}$ prática, essa função acabou sendo assumida pelos próprios professores das turmas de progressão, os quais foram designados pela SMED para voltarem em turno oposto ao de trabalho, com o intuito de promover, junto com os alunos dos ciclos I e II que encontravam dificuldades em acompanhar as atividades, uma espécie de reforço escolar, que se caracterizava por ser uma continuidade das atividades realizadas em sala de aula. Segundo os relatos, grande parte dos sujeitos que recebiam o reforço escolar eram alunos das turmas de progressão.

\section{Segundo momento: ciclos de formação humana (2006)}

No ano de 2005, a proposta dos ciclos de aprendizagem passou por novo processo de reestruturação. Assim, houve tentativas com relação à ampliação em mais um ano do ciclo II, que passaria a englobar a idade de 9, 10 e 11 anos e 11 meses; implantação do ciclo III para a idade de 12,13 e 14 anos e 11 meses, em duas escolas

14 Turmas de progressão foram criadas com o intuito de atender alunos que apresentassem defasagem entre idade e escolaridade. Detalhes sobre a organização dessas turmas, ver Cadernos Pedagógicos (2004, p. 23). 
da RME/VC. Nesse sentido, seria acrescentado ao campo dos conhecimentos do ciclo II a língua estrangeira; e organizar-se-ia o ciclo III em áreas de conhecimento. Estas áreas seriam linguagem (português, inglês, arte, ensino religioso), ciências físicas e naturais (matemática, ciências) e ciências humanas (história, geografia, educação física).

Associada a essa tentativa de ampliação dos ciclos em Vitória da Conquista, encontra-se também a mudança do nome: os ciclos de aprendizagem passaram a ser designados ciclos de formação humana, estando na base dessa mudança o estudo do desenvolvimento do ser humano (neurociências, psicologia, psicolinguística) e sua inserção no contexto sociocultural (antropologia, sociologia, comunicação), que exige formas de organização dos tempos de aprender.

Essa nova proposta pretendeu reestruturar as escolas, a partir do ano de 2006, da seguinte forma: ciclo I - alunos com idade de 6, 7, 8 anos e 11 meses; ciclo II alunos com idade de 9, 10,11 anos e 11 meses; ciclo III - alunos com idade de 12, 13 e 14 anos e 11 meses (Vitória da Conquista/SMED, 2005, p. 6).

A transformação do ciclo de aprendizagem em ciclo de formação humana em Vitória da Conquista pautou-se em modelos de organização em ciclos considerados bem-sucedidos no cenário nacional, tais como a escola ciclada de Belo Horizonte-MG.

É necessário acrescentar que a escola ciclada de Belo Horizonte, também conhecida como escola plural, segundo Castro (2000), tem como principal objetivo garantir a escolarização de todos e, ao mesmo tempo, assegurar a formação de todos. Ainda segundo essa autora, a referida escola propõe uma mudança radical nas estruturas excludentes, discriminatórias e hierarquizadas das instituições escolares, possibilitando a construção de uma escola mais democrática e igualitária.

São previstos nessa organização: respeito à diversidade dos ritmos de aprendizagem; garantia da permanência do aluno através de aprendizagens significativas; ênfase no desenvolvimento de aprendizagens fundamentais, tais como o aprender a aprender, aprender a fazer, aprender a conviver, aprender a ser. Em nível de operacionalidade, a escola ciclada de Belo Horizonte eliminou o regime seriado e instituiu três ciclos de formação básica, agrupando as crianças de acordo com sua faixa etária.

Gestores da SMED relataram, em momento de entrevista, que com essa nova versão da escola ciclada em Vitória da Conquista objetivou-se a construção de um espaço mais inclusivo, em que o aluno pudesse ser considerado o centro do processo. Todavia, os professores, diretores e coordenadores consultados nas escolas revelaram que se sentiam despreparados e receosos com a implantação dos ciclos de formação humana.

Parte dos sujeitos consultados queixou-se de que a mudança foi instaurada de cima para baixo. Nesse sentido, Gomes (2003, p. 42) alerta que a participação dos professores é essencial para a mudança, pois "não adianta tratar o professor como objeto nem na escola tradicional, nem na escola renovada". O referido autor ainda acrescenta que inovações tão delicadas exigem envolvimento pleno do magistério. Outra queixa apresentada pelos professores, diretores e coordenadores das escolas refere-se à falta de 
participação/informação dos alunos e dos pais nesse processo de mudança de propostas dos ciclos de aprendizagem para o de formação humana. Nesse sentido, Gomes (idem, ibidem) acrescenta que "igualmente, são importantes dois atores, a serem convencidos dos propósitos e das vantagens das inovações: os alunos e as suas famílias".

De acordo com os sujeitos consultados, nesse novo momento da proposta de ciclos conservou-se muito da dinâmica e das inovações iniciadas na proposta dos ciclos de aprendizagem. Entretanto, algumas modificações foram sugeridas, tais como:

a) Jornada ampliada, oferecida em contraturno, destinada aos alunos do ciclo II que necessitassem de intervenção pedagógica para ampliar seus conhecimentos;

b| Trabalho por meio dos projetos didáticos, tema gerador, complexo temático, com o intuito de promover a interdisciplinaridade;

c| Enturmação do educando e organização das classes obedecendo ao exclusivo critério da idade do educando;

d| Avanço interciclo, devendo este se dar de forma contínua, não permitindo a retenção dos alunos nos ciclos;

e| Turmas de progressão desaparecem nessa proposta, tendo seus alunos reagrupados conforme seus pares de idade.

\section{Terceiro momento: retorno ao ciclo de aprendizagem}

Nesse contexto, entre os anos de 2009 e 2010, a organização por ciclos passa por outras modificações, tais como a nova disposição das etapas que se reordenam em quatro ciclos, ficando assim constituídos: ciclo I - com a duração de três anos, compreendendo o período reservado à infância; ciclo II - com a duração de dois anos, compreendendo os anos correspondentes à pré-adolescência; ciclo III - com a duração de dois anos, compreendendo o final da pré-adolescência e início da adolescência; ciclo IV - com duração de dois anos, compreendendo o período inicial da adolescência. Havendo o regime de progressão continuada somente nos dois primeiros anos do ciclo I, e a partir do $3^{\circ}$ ano do ciclo I o regime de progressão regular por ano de estudo.

Novamente, associada a essas modificações encontra-se a alteração do nome: o ciclo de formação humana passa a ser novamente chamado de ciclo de aprendizagem. Contudo, não é possível dizer que houve um retorno à proposta de ciclos instaurada em 1998-2004, afinal o ciclo tem outra estrutura, especialmente no aspecto ligado à progressão continuada. Em síntese, podemos destacar as seguintes características, as quais garantem à proposta um novo direcionamento, distinto tanto daquele dos ciclos de formação humana (2006) quanto daquele dos ciclos de aprendizagem (2004):

a) A enturmação dos educandos e a organização das classes obedecendo ao critério de idade e de competência, considerando-se ainda a vida escolar no ano letivo anterior e o nível de aprendizagem do aluno;

b| A recuperação da aprendizagem, parte integrante do processo escolar, seria oferecida paralelamente ao período letivo, no mesmo turno das aulas regulares, cabendo a cada escola definir em seu projeto pedagógico a forma de recuperação paralela. 
Retomando as linhas: ciclos de aprendizagem

e ciclos de formação humana

Retomando as linhas desse primeiro eixo de análise referente à reestruturação curricular da RME/VC, destacam-se alguns aspectos percebidos como favoráveis pelos entrevistados no contexto dos ciclos de aprendizagem e dos ciclos de formação humana. Um dos aspectos positivos citado foi a ênfase dada à formação/capacitação permanente dos professores e a jornada ampliada de estudos (um tipo de reforço escolar), destinada a auxiliar os alunos dos ciclos I e II que encontravam dificuldades no transcorrer de sua escolarização.

De acordo com Mainardes (2006), é necessário reconhecer as diferenças entre as propostas de ciclos de aprendizagem e ciclos de formação. Os ciclos de aprendizagem representam uma ruptura menos radical, pois mantêm a reprovação ao final de dois ou três anos de ciclos, as mudanças propostas no currículo e na metodologia são mais superficiais, ou seja, nessa forma de organização ainda prevalecem as propostas de organização conservadoras da "escola tradicional".

Por sua vez, a tentativa de implantação dos ciclos de formação tem representado uma ruptura mais radical, pois objetiva eliminar totalmente a reprovação no ensino fundamental. Ainda conforme Mainardes (2006), nessa proposta há geralmente um investimento mais intenso na formação continuada dos professores, uma mudança mais radical no currículo e nas orientações metodológicas para o ensino e aprendizagem, tais como projetos de trabalho (Belo Horizonte) e complexos temáticos (Porto Alegre).

\section{TRAMAS DOS PROCESSOS DE IMPLEMENTAÇÃO DOS CICLOS NAS REDES MUNICIPAIS DE PORTO ALEGRE E VITÓRIA DA CONQUISTA: CONSIDERAÇÕES FINAIS E PROVISÓRIAS}

As experiências apresentadas neste texto mostram as possibilidades de transformação da escola. Estas ligadas à reformulação dos espaços e dos tempos escolares, sobretudo vinculadas à concepção que se tem de ensino e aprendizagem. Entretanto, é necessário salientar que os ciclos, como uma forma de organização escolar e de desenvolvimento do currículo, por uma perspectiva democrática e inclusiva, encontram-se em pleno processo de construção, enfrentando resistências e reformulações constantes. A organização curricular por ciclos apresenta, em diferentes momentos de gestão, avanços e retrocessos, o que é extremamente necessário para que as mudanças em relação à qualificação do ensino possam ser realizadas.

No que se refere ao complexo processo de democratização do ensino, podemos citar como exemplo a criação dos dispositivos que têm potencializado a presença de alunos com deficiência nas escolas e auxiliado na construção de estratégias de trabalho a esses alunos, bem como apoio aos professores e familiares desses alunos. Fazemos aqui alusão aos espaços especializados no ambiente da escola de ensino 
comum. Esses espaços, tanto na RME/POA ${ }^{15}$ como na $\mathrm{RME} / \mathrm{VC}$, funcionam como ação complementar ou suplementar ao trabalho realizado no ensino comum, e não em caráter substitutivo ao ensino comum, como ocorria com as escolas especiais.

Nesse sentido, percebe-se o avanço em ambas as redes em relação à valorização do processo de escolarização no ensino comum como sendo prioritário para a escolarização de crianças e adolescentes com deficiência. A valorização do espaço especializado no ensino comum como um apoio pedagógico pode ser compreendida como uma ação favorecedora à educação em uma perspectiva inclusiva, entendendo que a escola precisa construir estratégias pedagógicas diferenciadas que sejam acessíveis às especificidades dos alunos.

Quanto às resistências, destacamos a relação entre os professores e a lógica de uma organização ciclada. Em ambas as redes os professores apresentam dificuldades em entender o funcionamento da escola por ciclos, o que dificulta construir estratégias metodológicas em consonância com essa lógica. Em muitos casos, a escola continua a funcionar com a lógica do sistema seriado, de avaliação do resultado, organização das turmas por níveis de conhecimento, reprovação dos alunos que não atenderam às exigências curriculares. Ações essas que favorecem a exclusão dos alunos que não conseguem cumprir com êxito o cronograma anual, culpabilizando-os por seu suposto fracasso escolar. Nesse caso, muitas vezes se faz uma analogia entre os dois sistemas - seriado e ciclado -, como se isso fosse possível.

Uma reformulação importante em relação ao sistema ciclado refere-se à avaliação da aprendizagem. O debate referente ao modo mais adequado de avaliar a aprendizagem tornou-se emblemático e polêmico pela abertura do espaço escolar a todos. A perspectiva de uma "Escola para todos", democrática e de qualidade, colocou em xeque a escola construída com o objetivo de homogeneização dos modos de ser, saber e aprender. Com isso, muitas crianças e jovens que antes estavam à margem do processo de escolarização chegaram à escola e desorganizaram as noções históricas em relação ao que se considera aprendizagem.

Em consonância com a discussão sobre o que consideramos aprendizagem, a avaliação pautada na mensuração do saber também começou a ser questionada. A prática da avaliação, criada para definir quem são os alunos capazes de aprender e excluir os demais, não poderia mais ser embasada nos pilares da homogeneização em pleno processo de inclusão escolar. A organização curricular por ciclos entende que a avaliação é um processo pedagógico constante e que se refere ao contexto escolar, às práticas pedagógicas desenvolvidas com o aluno e à relação dele com o que foi discutido ao longo de um ano letivo. Portanto, avaliação não deveria ser entendida como resultado de um momento do aluno, mas como indício do movimento pedagógico mais amplo. Muda-se o foco do aluno e foca-se nas relações.

15 Espaço da educação especial no ensino comum, criado em caráter experimental em 1995 e denominado de SIR. 
Assim, passou-se a discutir a impertinência da avaliação realizada em momentos estanques, por meio de apenas um tipo de instrumento (geralmente prova) e utilizada apenas como um modo de inserir o aluno em categorias: bom, ótimo, mediano, que não aprende, com dificuldades.

As discussões em ambas as redes indicaram que o modo de apresentação da avaliação não deveria mais ser por notas, mas por pareceres que pudessem indicar os avanços dos alunos, apontar pontos frágeis que deveriam ser trabalhados, apresentar estratégias de trabalho utilizadas para favorecer as aprendizagens de cada um e de todos. Mas não apenas a apresentação deveria mudar, mas também a concepção de avaliação. Pensar em processo, em vez de resultado; pensar em relações de ensino e aprendizagem, em vez de focar-se no aluno.

Além disso, considerando que os ciclos não são pautados com a lógica de a aprendizagem se dar ao longo do ano letivo, mas ser constante, as redes indicaram que a escola, em seu conjunto, deveria pensar estratégias pedagógicas que favorecessem aos alunos avançar em seus estudos, sempre que possível. A intenção era de minimizar os altos índices de reprovação, que ao longo dos anos faziam com que os alunos evadissem da escola.

Muitas mudanças positivas foram realizadas em relação à avaliação, mas sabemos que tanto a $\mathrm{RME} / \mathrm{POA}^{16}$ como na RME/VC têm um longo caminho pela frente no que tange ao processo de avaliação da aprendizagem, pois mudar uma concepção cultural demanda anos e necessita muita discussão, avanços e retrocessos. Ambas as redes "engatinham" nesse sentido, já que, apesar de algumas práticas terem se modificado, a lógica predominante ainda é aquela que avalia o que aluno demonstrou aprender em um tempo determinado, sem que a avaliação seja vista pelo professor como um instrumento de reflexão e modificação de seu trabalho.

A organização curricular por ciclos desacomoda e instiga discussões que há muito não se fazia na escola, como: afinal, qual o sentido da repetência? $\mathrm{O}$ que ensinar aos nossos alunos? Como ensinar? Todas as crianças aprendem?

Indubitavelmente, a mudança de escola seriada para ciclada evoca uma ressignificação das crenças e valores historicamente construídos em relação à escola e à educação, além de ampliar o acesso à escola, sobretudo em relação aos alunos com deficiência. Tal ressignificação é de um nível muito mais complexo, pois representa deslocamentos epistemológicos e necessidade de mudanças culturais. Apesar de as experiências de escolas com organização curricular por ciclos serem bastante variadas em suas implantações e concepções, e de representarem significativa quantidade de experiências, ainda são bastante recentes e não se consolidaram como uma estrutura curricular compreendida por todos.

A organização curricular por ciclos ainda não se firmou como outra forma de pensar e fazer escola, rompendo com a lógica historicamente construída da es-

16 Sobre avaliação da aprendizagem nos ciclos de formação em Porto Alegre, ler Ana Carolina Christofari (2008). 
cola seriada. No entanto, constituiu-se como um desafio constante pensar a escola de outro modo, com outras configurações capazes de atender às necessidades dos alunos. De se pensar a escola como espaço do encontro com a diversidade humana como fator enriquecedor e necessário ao aprendizado de todos.

\section{REFERÊNCIAS}

Azevedo, José Clóvis de. Escola cidadã: políticas e práticas. In: Reunião Anual DA ANPEd, 23., 2000, Caxambu. Anais... Caxambu: Educação não é privilégio, 2000, Trabalho encomendado.

Baptista, Claudio Roberto; Dorneles, Beatriz. Políticas de inclusão escolar no Brasil: descrição e análise do município de Porto Alegre. In: Prieto, Rosângela. Políticas de inclusão escolar no Brasil: descrição e análise de sua implementação em municípios das diferentes regiões. Trabalho encomendado do GT-15 Educação Especial na 27a Reunião Anual da ANPEd. Caxambu, 2004.146 p.

Barbosa, Maria Carmem Silveira. Infância, escola e uma nova compreensão de temporalidade. In: Moll, Jaqueline (Org.). Ciclos na escola, tempos na vida: criando possibilidades. Porto Alegre: Artmed, 2004. p. 65-71.

Barretto, Elba Siqueira de Sá; Sousa, Sandra Maria Zákia Lian. Ciclos: estudos sobre as políticas implementadas no Brasil. In: Reunião AnUAL DA ANPEd, 27., 2004, Caxambu. Anais... Caxambu: Sociedade, democracia e educação: qual universidade?, 2004, 1 CD-ROM.

; Mit rulis, Eleny. Os ciclos escolares: elementos de uma trajetória. Cadernos de Pesquisa, São Paulo, Fundação Carlos Chagas, n. 108, p. 27-48, nov. 1999.

BRIDI, Fabiane Romano de Souza. O lugar das diferenças e a configuração dos espaços escolares. 2004. Dissertação (Mestrado em Educação) - Programa de Pós-Graduação em Educação, Faculdade de Educação, Universidade Federal do Rio Grande do Sul. Porto Alegre, 2004.

Cadernos PedaGógicos. 2. ed. Secretaria Municipal de Educação do Município de Porto Alegre, n. 9, p. 23, 1999.

Castro, Maria Céres Pimenta Spínola. Escola plural: a função de uma utopia. In: Reunião Anual da ANPEd, 23., 2000, Caxambu. Anais... Caxambu: Educação não é privilégio, 2000, Trabalho encomendado.

Christofari, Ana Carolina. Avaliação da aprendizagem e inclusão escolar: trajetórias nos ciclos de formação. 2008. Dissertação (Mestrado em Educação) - Programa de Pós-Graduação em Educação, Faculdade de Educação, Universidade Federal do Rio Grande do Sul, Porto Alegre, 2008.

Freire, Paulo. Pedagogia do oprimido. 15. ed. Rio de Janeiro: Paz e Terra, 1985.

Gomes, Cândido. Alberto. Quinze anos de ciclos no ensino fundamental: uma análise dos percursos. Revista Brasileira de Educação, Rio de Janeiro, ANPEd; Campinas, Autores Associados, n. 25, p. 39-52, jan./abr. 2003. 
KLovan, Cristiane Fiqueiró. Perspectivas de professores sobre o ensino por ciclos de formação em Porto Alegre: uma análise sociológica da implantação e do momento atual. 2008. Dissertação (Mestrado em Educação) - Programa de Pós-Graduação em Educação, Faculdade de Educação, Porto Alegre, 2008.

Leite, Maria Iza Pinto de Amorim. Méritos e pecados do ciclo no ensino fundamental: análise da implantação do ciclo de aprendizagem nas escolas da rede municipal de Vitória da Conquista. 1999. Dissertação (Mestrado em Ciências Sociais) - Programa de Pós-Graduação em Educação, Faculdade de Educação, Pontifícia Universidade Católica de São Paulo, São Paulo, 1999.

Mainardes, Jefferson. Organização da escolaridade em ciclos no Brasil: revisão da literatura e perspectivas para a pesquisa. Educação e Pesquisa, São Paulo, FEUSP, v. 32, n. 1, p. 11-30, jan./abr. 2006.

Moll, Jaqueline. Ciclos na escola e tempos na vida. Porto Alegre: Artmed, 2004.

Perrenoud, Philippe. Os ciclos de aprendizagem: um caminho para combater o fracasso escolar. Porto Alegre: Artmed, 2004.

Piaget, Jean. A linguagem e o pensamento da criança. 7. ed. São Paulo: Martins Fontes, 1999.

. Psicologia e pedagogia. 9. ed. Rio de Janeiro: Forense Universitária, 2003.

Tezzari, Mauren Lucia. "A SIR chegou...". Sala de Integração e Recursos e a inclusão na rede municipal de ensino em Porto Alegre. 2002. Dissertação (Mestrado em Educação) Programa de Pós-Graduação em Educação, Faculdade de Educação, Universidade Federal do Rio Grande do Sul, Porto Alegre, 2002.

Vitória da Conquista (Município). Secretaria Municipal de Educação. Núcleo Pedagógico da SMED. Cartilha tira-dúvidas: ciclo de formação humana. Vitória da Conquista: Prefeitura Municipal de Vitória da Conquista, 2005.

Vygotsky, Lev Semenovitch. Formação social da mente. São Paulo: Martins Fontes, 1991. Warnock, H. M. (Org.). Relatório Warnock 1978. Necessidades educativas especiais. London: Her Majesty's Stationery, 1978. Disponível em: <http://www.educationengland. org.uk/documents/warnock/>. Acesso em: 15 nov. 2011.

Xavier, Maria Luiza Merino de Freitas. Os incluídos na escola: o disciplinamento nos processos emancipatórios. 2003. Tese (Doutorado em Educação) - Programa de Pós-Graduação em Educação, Faculdade de Educação, Universidade Federal do Rio Grande do Sul, Porto Alegre, 2003.

\section{SOBRE AS AUTORAS}

Ana Carolina Christofari é professora da rede municipal de educação de Porto Alegre e doutoranda em educação pela Universidade Federal do Rio Grande do Sul (UFRGS).

E-mail: carolc29@ig.com.br 
Kátia Silva Santos é professora do Instituto Federal de Educação Ciências e Tecnologia da Bahia (IFBA) e doutoranda em educação pela Universidade Federal do Rio Grande do Sul (UFRGS).

E-mail: katiapedagogi@yahoo.com.br

Recebido em agosto de 2010

Aprovado em março de 2012 


\section{ANA CAROLINA CHRISTOFARI E KÁTIA SILVA SANTOS}

\section{Políticas locais de reestruturação curricular por ciclos: avanços e desafios}

O texto tem como ponto de partida duas pesquisas de mestrado realizadas entre os anos de 2005 e 2008 na Universidade Federal do Rio Grande do Sul (UFRGS). Tais estudos abordaram políticas locais de reestruturação curricular por ciclos em diferentes Redes Municipais de Ensino (RME): a de Porto Alegre-RS e a de Vitória da Conquista-BA. As descrições enfatizam os possíveis efeitos das políticas atuais de inclusão escolar no processo de escolarização. Ambas as redes, organizadas por ciclos, têm como objetivo uma compreensão de escolarização como processo contínuo, ininterrupto. Em suas diretrizes, esses contextos adotam indicações de que o processo educacional seja orientado pelo princípio de uma educação democrática e acessível a todos.

Palavras-chave: educação; ciclos de formação; currículo.

\section{Local policies of curriculum restructuring per cycles: advances and challenges}

The starting point of this text are two Master studies conducted from 2005 to 2008 at the Federal University of Rio Grande do Sul. Such studies addressed local policies of curriculum restructuring per cycles in two Municipal Education Systems: Porto Alegre (Rio Grande do Sul state) and Vitoria da Conquista (Babia state). The descriptions emphasize the possible effects of current policies of school inclusion on the schooling process. Organized per cycles, both systems aim at an understanding of schooling as a continuous, uninterrupted process. These systems' guidelines indicate that the educational process should be guided by the principle of democratic education accessible to all.

Keywords: education; training cycles; curriculum.

\section{Políticas locales de restructuración curricular por ciclos: avances y desafíos}

Este texto toma como punto de partida dos investigaciones de maestría llevadas a cabo entre los años de 2005 y 2008, en la Universidade Federal do Rio Grande do Sul. Estos estudios se han ocupado de las politicas locales de reestructuración curricular organizada por ciclos en diferentes Redes Municipales de Enseñanza (RME): la de Porto Alegre-RS y la de Vitória da Conquista-BA. Las descripciones dan relieve a los posibles efectos de las politicas actuales de inclusión escolar en el proceso de escolarización. Ambas redes, organizadas por ciclos, tienen como objetivo la comprensión de la escolarización como proceso continuo e ininterrumpido. Estos contextos adoptan en sus directrices indicaciones de que el proceso educativo se rige por el principio de una educación democrática y al alcance de todos.

Palabras clave: educación; ciclos de formación; currículo. 